\title{
Microstructural and Hardness Evolution in a Duplex Stainless Steel Processed by High-Pressure Torsion
}

\author{
Ming Ma ${ }^{1,2}$, Hua Ding ${ }^{3, *}$, Yi Huang ${ }^{4,5, *}$, Cheng Wei Tian ${ }^{1}$ and Terence G. Langdon ${ }^{5}(\mathbb{C}$ \\ 1 School of Materials Science and Engineering, Northeastern University, Shenyang 110819, China; \\ mingma1986@sylu.edu.cn (M.M.); gaoliang@changan.com (C.W.T.) \\ 2 School of Material Science and Engineering, Shenyang Ligong University, Shenyang 110159, China \\ 3 State Lab of Rolling and Automation, Northeastern University, Shenyang 110819, China \\ 4 Department of Design and Engineering, Faculty of Science and Technology, Bournemouth University, Poole, \\ Dorset BH12 5BB, UK \\ 5 Materials Research Group, Department of Mechanical Engineering, University of Southampton, \\ Southampton SO17 1BJ, UK; langdon@soton.ac.uk \\ * Correspondence: dingh@smm.neu.edu.cn (H.D.); yhuang2@bournemouth.ac.uk (Y.H.)
}

Received: 22 November 2020; Accepted: 9 December 2020; Published: 15 December 2020

\begin{abstract}
The duplex stainless steel 2205, designated DSS2205 and having a duplex structure comprising ferrite and austenite phases, was processed by high-pressure torsion (HPT) and the microstructural and hardness evolutions were investigated after various HPT revolutions and at different positions within the specimens. The results show that the grain refinement induced by severe deformation processing is different in the ferrite and austenite phases such that the ferrite grains are refined via dislocation subdivision, whereas grain refinement in the austenite phase depends mainly on the interaction of dislocations and twin boundaries at relatively low strains. When the numbers of revolutions increases, the grain refinement in austenite restricts the occurrence of deformation twinning so that dislocation slip becomes dominant. During HPT processing, the effect of the phase boundaries on the mechanical properties of the alloy is very significant. The results show the average width between two adjacent phases and the hardness of the alloy are generally consistent with the classical Hall-Petch relationship.
\end{abstract}

Keywords: duplex stainless steel; Hall-Petch relationship; high-pressure torsion; severe plastic deformation; ultrafine grains

\section{Introduction}

Bulk ultrafine-grained (UFG) metals with grain sizes of $<1 \mu \mathrm{m}$ and nanocrystalline (nc) metals with grain sizes of $<100 \mathrm{~nm}$ have become especially attractive over the last decade because of their improved strength and ductility [1-7]. In recent years, processing through the application of severe plastic deformation (SPD) has been considered the most effective technique for producing grain refinement in the form of UFG and nc metallic materials. Among the numerous SPD processing techniques currently available, high-pressure torsion (HPT) has been of major interest due to its potential for producing smaller grains $[8,9]$ and higher fractions of grain boundaries having high angles of misorientation [10]. In HPT processing, the sample is generally in the form of a thin disk and it is placed between two massive anvils and subjected to a high applied pressure and concurrent torsional straining [11]. For an ideal rigid cylinder, the shear strain induced by HPT can be calculated from the equation [12]

$$
\gamma=2 \pi N r / h
$$


where $N$ is the number of revolutions during HPT, $r$ is the distance from the center of the disk and $h$ is the thickness of the specimens, respectively. From this relationship, two reasonable inferences may be drawn. First, the shear strain and microstructural evolution, and therefore the mechanical properties of the material, should be the same at all points lying at the same distance from the center of the disk. Second, the shear strain in the center of the disk is zero and the strain is linearly distributed along all radial directions. In practice, however, there are several experimental results that differ from these conclusions. For example, it was found that a reasonably saturated hardness may be achieved throughout HPT disks, both at the surface [13-16] and internally [17,18], through the application of a sufficiently large shear strain. These apparent differences between theory and experiment have been well explained through the application of strain gradient plasticity modeling to HPT processing [19].

In recent years, HPT has been used to process many single-phase metallic materials and the corresponding microstructures and property evolutions have been carefully investigated. The results showed that there are generally two basic types of SPD-induced grain refinement. For body-centered cubic (bcc) materials, including, for example, ferritic steel, the refinement in microstructure is mainly dependent on dislocation activities including dislocation accumulation and the tangling and rearrangement of dislocations that subdivide the larger grains into many smaller grains with the formation of dislocation cells and low-angle and subsequently high-angle grain boundaries (GBs) [20-22]. For austenite and similar materials, the mechanism of SPD-induced grain refinement is dominated by twin boundary subdivision and interactions between the twin boundaries and dislocations [23-25]. It was proposed that the grain refinement of each constituent phase in duplex stainless steel is similar to its own refinement mechanism as in the corresponding single-phase alloys during high-pressure torsion processing [26]. Nevertheless, more information is required to fully document the relationship between the grain refinement mechanism and the numbers of revolutions applied in HPT processing. Furthermore, although results are available on the grain refinement mechanism in ferrite and austenite, the quantitative relationship between the microstructural evolution and the overall hardness of the alloy has not yet been investigated.

Accordingly, the present research was initiated to evaluate the effect of the processing of DSS2205 through different numbers of HPT revolutions and the process of SPD-induced microstructural refinement in austenite and ferrite was investigated systematically at different deformation stages.

\section{Experimental Materials and Procedures}

The chemical composition of the duplex stainless steel (DSS2205) is shown in Table 1. The duplex stainless steel was supplied in the hot-rolled plus normalized state, with hot rolling temperatures of $1050-1200{ }^{\circ} \mathrm{C}$. In the as-received state, the volume fractions of austenite and ferrite phases were $54.7 \%$ and $45.3 \%$, respectively. The as-received stainless steel was machined into cylindrical rods having diameters of $10 \mathrm{~mm}$ and HPT disks were sliced from these rods with thicknesses of $\sim 1.0 \mathrm{~mm}$ and then polished to final thicknesses of $0.85 \mathrm{~mm}$.

Table 1. Composition of the experimental steel, wt.\%.

\begin{tabular}{cccccccc}
\hline Element & $\mathbf{C r}$ & $\mathbf{M o}$ & $\mathbf{N i}$ & $\mathbf{N}$ & $\mathbf{M n}$ & $\mathbf{C}$ & $\mathbf{S i}$ \\
\hline DSS2205 & 23.61 & 3.36 & 5.12 & 0.19 & 1.67 & 0.019 & 0.37 \\
\hline
\end{tabular}

HPT processing was carried out under an applied pressure of $6.0 \mathrm{GPa}$ with disks processed through totals, $N$, of $1 / 4,1 / 2,1,5,10$ and 20 revolutions with a strain rate of $1 \mathrm{rpm}$. This processing was conducted under quasi-constrained conditions $[27,28]$ in which there is a small outflow of material around the periphery of the disk during the torsional straining. After HPT processing, the thicknesses of the specimens were reduced to approximately $0.70 \mathrm{~mm}$. Following processing, the deformed disks were electropolished in a solution of $\mathrm{HClO}, \mathrm{C}_{2} \mathrm{H}_{5} \mathrm{OH}$ and $\mathrm{H}_{2} \mathrm{O}$ and then electrolytically polished in a $10 \mathrm{wt} . \% \mathrm{NaOH}$ solution for examination by optical microscopy (OM). A quantitative characterization 
of the microstructure was obtained for each condition and at least twenty microstructural images were selected randomly for measurements on each specimen. The microstructural evolution was evaluated using an optical microscope (DSX500, OLYMPUS, Tokyo, Japan) and an FEI-Tecnai transmission electron microscope (TEM) (G20, FEI, Hillsboro, Oregon, United States). The Vickers microhardness was measured on specimens after various values of $\mathrm{N}$ and at selected positions on the disks using a microhardness tester (HMV-1ADW, SHIMADZU, Kyoto, Japan) with a load of $50 \mathrm{~g}$ and a dwell time for each measurement of $10 \mathrm{~s}$.

\section{Experimental Results}

\subsection{Evolution in Microhardness after HPT Processing}

The values recorded for the Vickers microhardness, Hv, are plotted in Figure 1a for various numbers of revolutions from $1 / 4$ to 20 with data for the as-received material shown as the lower line at $\mathrm{Hv} \approx 315$. As anticipated, after HPT processing, both the shear strain and the measured hardness increase with increasing distance from the center of the disk. This general trend is consistent for all numbers of revolutions, but after 10 and 20 revolutions, the values of $\mathrm{Hv}$ tend towards a constant value at distances larger than $\sim 1000 \mu \mathrm{m}$. This effect is illustrated more directly in Figure $1 \mathrm{~b}$ by plotting the individual hardness values against the number of HPT revolutions at three different distances from the disk centers. The trend towards a saturation value is visible at radial distances of 2500 and $4900 \mu \mathrm{m}$.
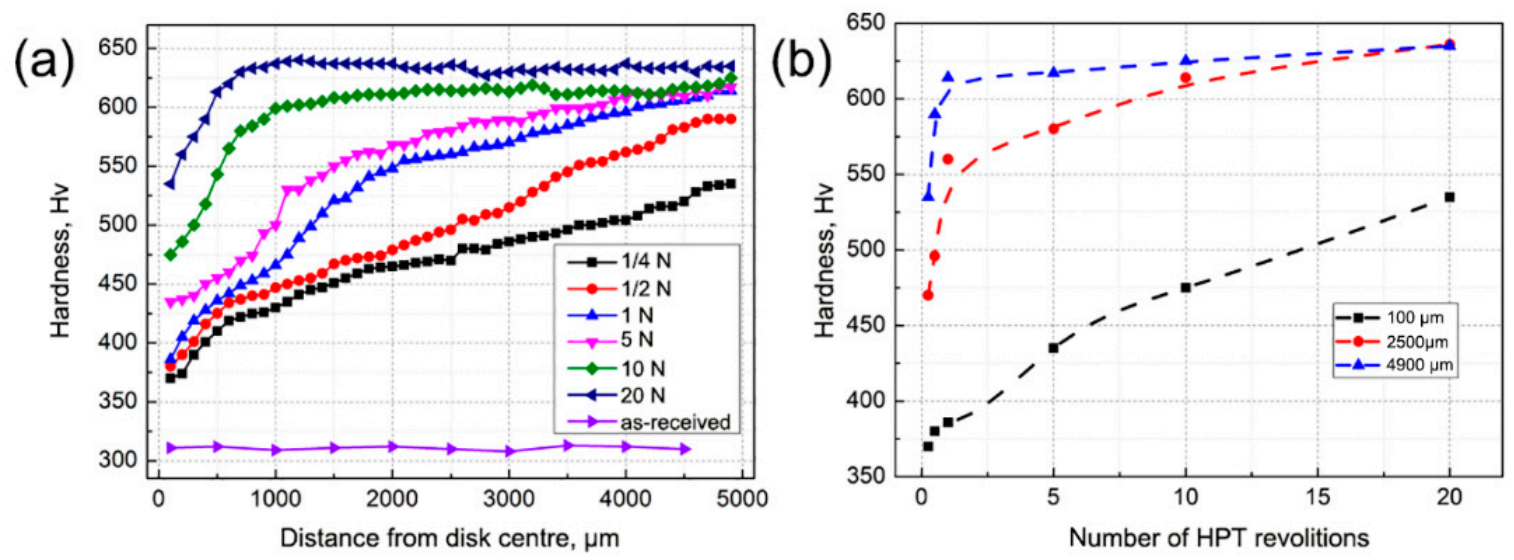

Figure 1. Vickers hardness distributions after high-pressure torsion (HPT) processing showing (a) the relationship between hardness and distance from the disk center for different numbers of revolutions and (b) the relationship between hardness and the numbers of revolutions with different distances from the disk center.

\subsection{Microstructural Evolution after HPT Processing}

\subsubsection{The Gradient Distributed Microstructure}

Figure 2a,b show representative microstructures of the ferritic and austenitic phase boundaries at two different magnifications and at two different selected positions after HPT processing through a $1 / 4$ revolution, where the light and dark areas represent austenite and ferrite, respectively. Due to the limited amount of deformation after only $1 / 4$ turn, the microstructure remains coarse in the central region of the disk and the phase boundaries are smooth in appearance, as shown in Figure 2a. At a distance from the center of $\sim 2500 \mu \mathrm{m}$, as shown in Figure $2 \mathrm{~b}$, the microstructure is clearly refined even after only a $1 / 4$ turn and the phase boundaries are curved due to interactions between the phase boundaries and the dislocations introduced during the HPT processing. 


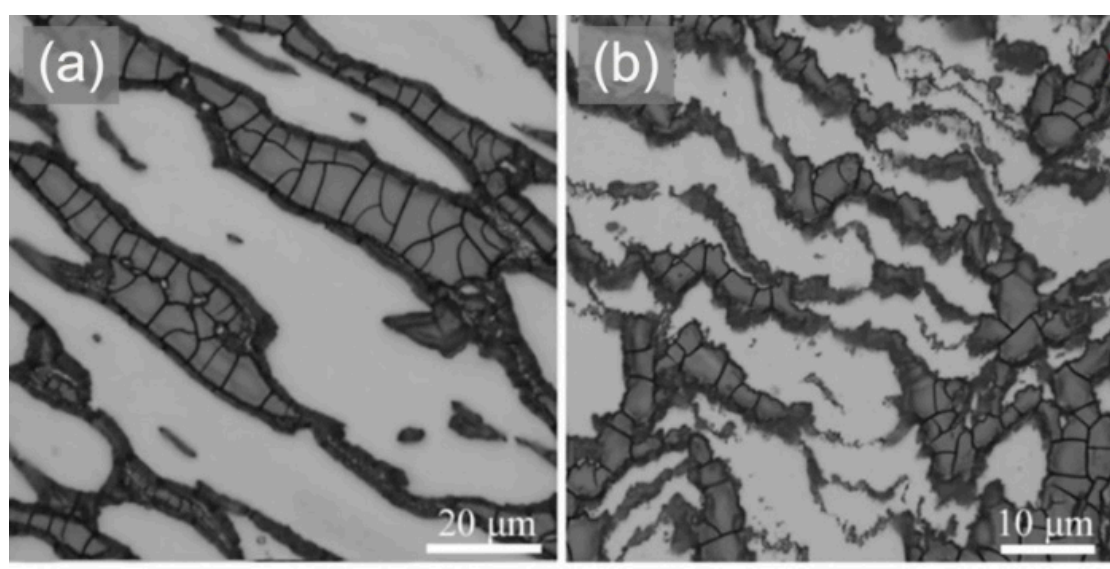

Figure 2. Micromorphology of the ferrite and austenite phase boundaries (a) in the central region of the disk and (b) $2500 \mu \mathrm{m}$ from the center.

Figure 3 shows OM images from the center (on left) to the edge (on right) with various numbers of HPT revolutions: the numbers of turns are (a) $1 / 4$, (b) $1 / 2$, (c) 5 and (d) 20 . It can be seen that both phases remain essentially as relatively thin strips as the torsional straining proceeds. Using an analogy similar to the significance of the pearlite spacing in medium-high carbon steels, the average width of both of these two phases, $\chi$, may be defined to describe the refinement in the microstructure during the HPT process as given by

$$
x=\left(x_{\gamma}+x_{\delta}\right) / 2
$$

where $\chi_{\gamma}$ and $\chi_{\delta}$ represent the widths of adjacent austenite and ferrite domains, respectively, and the quantitative average value of $\chi$ is recorded in Table 2 at different distances from the disk centers. As presented in Figure $3 \mathrm{a}$ for $N=1 / 4$, the distribution of the austenite domains (not the austenite grains) in the central position deviated from the shear direction and the microstructure remained coarse, indicating the occurrence of only very limited straining in this region. By contrast, at the edge of the specimen, the microstructure was refined so that the values of $\chi$ decreased from $\sim 15.06$ at the center to $\sim 4.89 \mu \mathrm{m}$ near the edge. When $N=1 / 2$, the shear strain in the center was significantly enhanced and the microstructure was refined so that the value of $\chi$ decreased to $\sim 8.89 \mu \mathrm{m}$. There was similar refinement in the phase domains in other positions in the specimens so that at $N=20$, and both the austenite and ferrite domains in the center were further refined and the value of $\chi$ was $\sim 4.80 \mu \mathrm{m}$ in the central region and $\sim 3.42 \mu \mathrm{m}$ near the edge. It is readily apparent that the microstructures in the centers of the disks were refined drastically when the numbers of revolutions increased. However, the values of $\chi$ at the edge remained very similar after 5 and 20 revolutions. It is noted that these microstructural observations are consistent both with the hardness measurements in Figure 1 and with a comprehensive review of the evolution in hardness in metals processed by HPT [29].

Table 2. The values of average width $(\chi)$ with various revolutions and distances to the centers of the specimens.

\begin{tabular}{ccccc}
\hline Revolutions & \multirow{2}{*}{$\mathbf{1 / 4}$} & $\mathbf{1} / \mathbf{2}$ & $\mathbf{5}$ & $\mathbf{2 0}$ \\
\cline { 1 - 3 } Distance $(\boldsymbol{\mu m})$ & & & & \\
\cline { 1 - 5 } $0-500$ & $15.06 \mu \mathrm{m}$ & $8.89 \mu \mathrm{m}$ & $6.20 \mu \mathrm{m}$ & $4.80 \mu \mathrm{m}$ \\
$1000-1500$ & $10.81 \mu \mathrm{m}$ & $7.61 \mu \mathrm{m}$ & $5.56 \mu \mathrm{m}$ & $4.82 \mu \mathrm{m}$ \\
$2250-2750$ & $7.19 \mu \mathrm{m}$ & $5.78 \mu \mathrm{m}$ & $4.87 \mu \mathrm{m}$ & $4.24 \mu \mathrm{m}$ \\
$3500-4000$ & $5.22 \mu \mathrm{m}$ & $4.99 \mu \mathrm{m}$ & $4.31 \mu \mathrm{m}$ & $3.94 \mu \mathrm{m}$ \\
$4500-5000$ & $4.89 \mu \mathrm{m}$ & $4.82 \mu \mathrm{m}$ & $3.58 \mu \mathrm{m}$ & $3.42 \mu \mathrm{m}$ \\
\hline
\end{tabular}




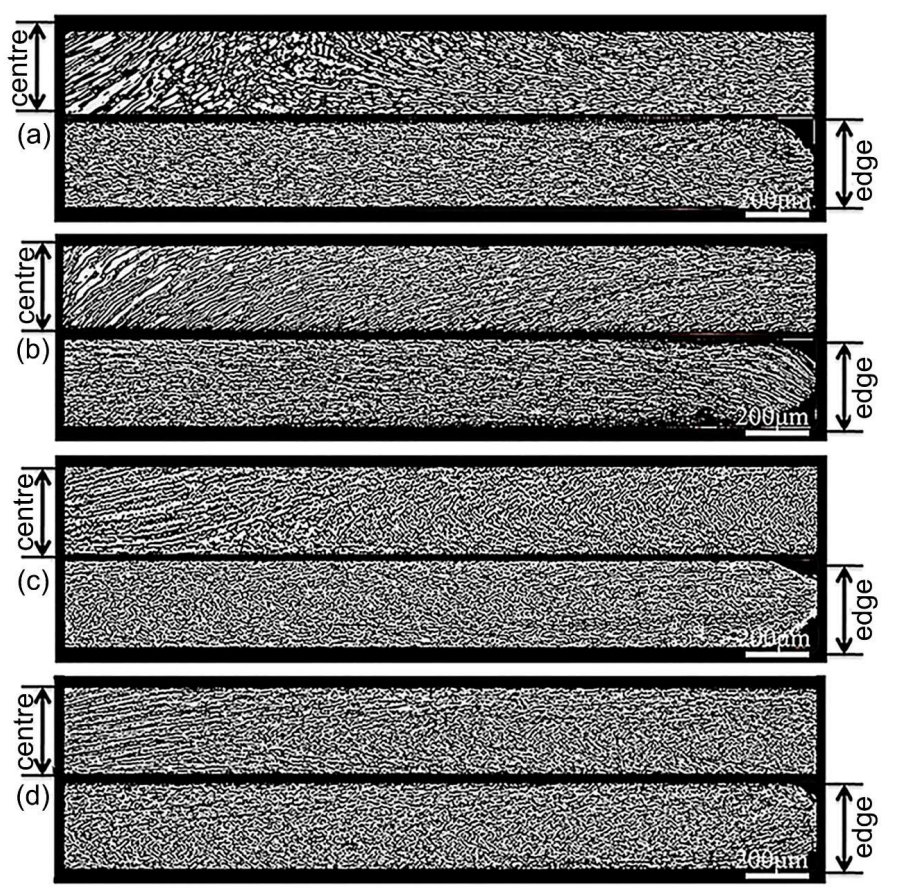

Figure 3. OM images of longitudinal sections from the center (on left) to the edge (on right) with different numbers of HPT revolutions after (a) 1/4, (b) 1/2, (c) 5 and (d) 20 turns.

\subsubsection{Microstructural Evolution in the Two Constituent Phases}

Since the highest hardness values and the greatest microstructural evolution occur at the edge of the disks, Figure 4 shows representative TEM images at the edges of specimens before and after various numbers of revolutions in HPT. These images relate to (a) the as-received material prior to HPT processing, (b) austenite after $N=1 / 4$ turn, (c) austenite and ferrite after $N=1 / 2$ turn, (d) austenite after $N=1 / 2$ turn, (e) ferrite after $N=1 / 2$ turn, (f) austenite after $N=1$ turn, (g) austenite after $N=1$ turn at a higher magnification, (h) austenite after $N=5$ turns, (i) austenite and ferrite after $N=5$ turns, (j) austenite and ferrite after $N=10$ turns, (k) the electron diffraction pattern from region A in Figure $4 \mathrm{j}$, (l) the electron diffraction pattern from region B in Figure 4j, (m) austenite and ferrite after $N=20$ turns, (n) the electron diffraction pattern from region A in Figure $4 \mathrm{~m}$ and (o) the electron diffraction pattern from region B in Figure $4 \mathrm{~m}$.

It is readily apparent from Figure $4 \mathrm{a}$ that the microstructure before HPT was very coarse for both constituent phases. When the deformation proceeds to $1 / 4$ turn as shown in Figure $4 \mathrm{~b}$, there are deformation twins in austenite which is similar after HPT processing to other materials having low stacking fault energies such as austenitic stainless steel, TWIP steel and $\mathrm{Cu}-\mathrm{Al}$ alloys [23,25,26,30]. As the revolutions increase to $1 / 2$ turn, the numbers of dislocations near the phase boundaries increase, as shown in Figure 4c, due to the phase boundaries which interfere with dislocation mobility. It is noted after $1 / 2$ turn that there are also some tangled dislocations adjacent to the deformation twins in austenite which suggests the occurrence of a mixed deformation mechanism comprising deformation twinning and dislocation glide, as shown in Figure 4d. In ferrite, due to the higher level of the stacking fault energy and the consequent decrease in the separations between the Shockley partials, many of the deformation dislocations are annihilated by climb or cross-slip and others become rearranged into dislocation cells after 1/2 turn, as is evident in Figure 4e.

Continuing the HPT processing to 1 turn, there are shear bands in austenite and the twin boundaries become less clearly defined, as shown in Figure 4f. There are also many cells that are formed near the shear bands, as shown in Figure 4g. Increasing to 5 turns, the number of dislocation cells in both the austenite and ferrite phases increases rapidly and their size decreases. A further increase in processing to 10 and 20 turns leads to the formation of numerous high-angle grain boundaries that 
are formed, as in other SPD processing techniques [31], from the dislocations introduced by the HPT processing. The presence of these ultrafine grains leads to rings in the relevant electron diffraction patterns, as shown in Figure 4.
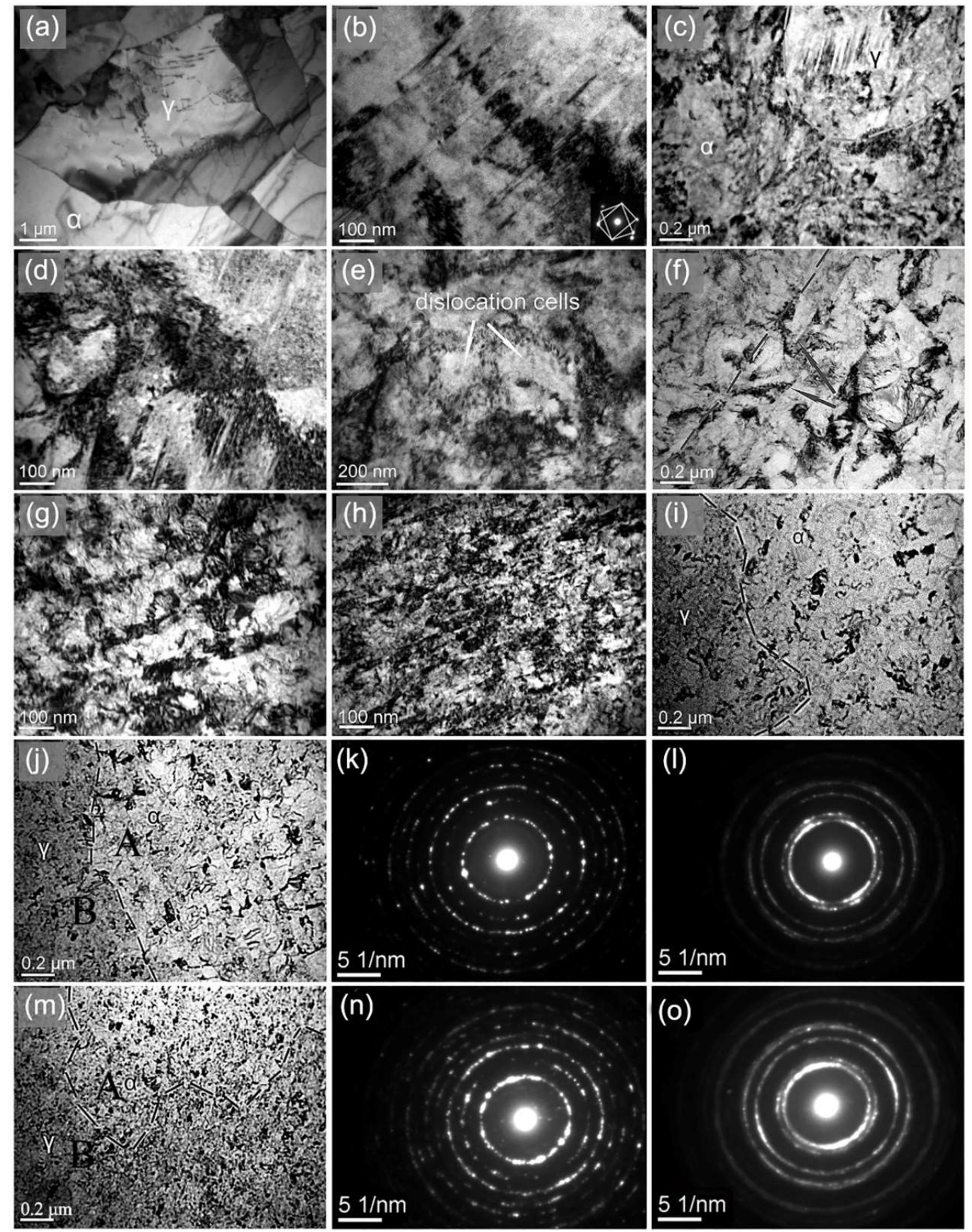

Figure 4. TEM images at the edge of specimens before and after different numbers of revolutions: (a) the as-received material; (b) 1/4 revolution, austenite; (c) 1/2 revolution, austenite and ferrite; (d) 1/2 revolution, austenite; (e) 1/2 revolution, ferrite; (f,g) 1 revolution, austenite at two different magnifications; (h) 5 revolutions, austenite; (i) 5 revolutions, austenite and ferrite; (j) 10 revolutions, austenite and ferrite; (k) electron diffraction pattern from region A in Figure 4j; (1) electron diffraction pattern from region B in Figure 4j; (m) 20 revolutions, austenite and ferrite; (n) electron diffraction pattern from region A in Figure 4m; (o) electron diffraction pattern from region B in Figure $4 \mathrm{~m}$. 


\section{Discussion}

\subsection{The SPD-Induced Grain Refinement Mechanism in the Austenite and Ferrite Phases}

This study reveals that the microstructure of the duplex stainless steel can be significantly refined through HPT processing and this leads to an enhancement in the mechanical properties as measured by the values of the Vickers microhardness. Nevertheless, the results are significant because they show also that the grain refinement mechanism is different in each constituent phase. For the ferrite phase, the refinement occurs mainly through the interactions between deformation dislocations. Dislocation cells are visible in Figure 4c,e. As the deformation continued into 10 turns of HPT processing, the size of the ferrite grains sharply decreased to $\sim 0.1-0.2 \mu \mathrm{m}$ (Figure 4j) and high-angle boundaries were formed. During this process, the deformation dislocations which are not annihilated by climb and cross-slip become rearranged into dislocation cells and then transform into grains having grain boundaries with high angles of misorientation [32]. In austenite in the early stages of the HPT processing, deformation twinning occurs in the coarse austenite grains due to the lower stacking fault energy, as shown in Figure $4 \mathrm{~b}$. As the numbers of revolutions increases, many dislocations tangle through dislocation slip within austenite, and the interaction between dislocations and twin boundaries may be observed in Figure $4 \mathrm{~d}$. As the deformation continues, the grain size of austenite further decreases, as shown in Figure $4 \mathrm{~m}$, and at the same time, the deformation twining in austenite disappears so that dislocation slip dominates the deformation behavior of austenite. Based on an earlier report [25], a de-twinning process may occur in austenite where partial dislocations interact with twin boundaries to produce partial dislocations that glide on the twin boundaries. Similar results were also reported in other earlier investigations [33-35]. It appears that this mechanism increases the twin boundary spacing and then transforms the twin boundaries into conventional high-angle grain boundaries through dislocation-twin boundary interactions which also serve to refine the austenite grains.

Deformation twining is usually caused by twin dislocation movement when the stress reaches a certain critical value. Therefore, any factors that hinder the movement of the twin dislocations will increase the critical stress for deformation twinning. In a study of the deformation behavior of fine-grained TWIP steel, it was considered that the absence of deformation twinning was the result of grain refinement in the alloy [36]. This suggests that the effect of grain size on the critical stress for deformation twining may be expressed through the classical Hall-Petch relationship which is given by [36]

$$
\tau_{t w}=\tau_{0}+\frac{K_{t w}^{H-P}}{\sqrt{D}}
$$

where $\tau_{0}$ and $\tau_{t w}$ are the critical stress of deformation twining for single-crystal and polycrystalline materials, respectively, $K_{t w}^{H-P}$ corresponds to the Hall-Petch coefficient for the deformation twining and $D$ is the grain size for the polycrystalline material.

According to Equation (3), the critical stress activating the mechanism of deformation twinning increases directly with a decrease in the grain size and therefore the grain refinement may significantly suppress the formation of deformation twins. In this investigation using HPT processing, the shear strain was enhanced at the edge of the disk and this means the austenitic grains were refined into several hundreds of nanometers even in the early stages of deformation. As a result, the increase in $\left(\tau_{t w}-\tau_{0}\right)$ suppresses the deformation twining and induces the formation of shear bands. Thus, it is concluded that, during the HPT processing of duplex stainless steels, the plastic deformation behavior of austenite in terms of dislocation slip or deformation twining is affected by the size of the grains. When a relatively high number of revolutions is imposed, the austenite grains are then further refined by the reactions between the twin boundaries and dislocations. It follows, therefore, that dislocation slip tends to dominate the deformation behavior of austenite as the deformation continues. 


\subsection{Microstructural Refinement Induced Hardening}

As already noted, the size of the phase domains decreases significantly with increasing revolutions during HPT processing, especially in the vicinity of the centers of the specimens. It has been suggested that the hardness of DSS is relatively insensitive to the specific shear strain patterns but, instead, it is more closely related to the widths of the austenite and ferrite phase domains [37]. Nevertheless, there is an absence of quantitative research supporting this suggestion.

Recent observations on HPT processing of bi-metallic laminates like stacked $\mathrm{Al} / \mathrm{Cu}$ and $\mathrm{Al} / \mathrm{Ni}$ demonstrated that, in addition to the in-plane shear strain, there is also mass transfer within the samples due to the development of turbulent eddy flows within the sample cross-sections during the HPT processing and this helps to develop numerous fine lamellar $\mathrm{Al} / \mathrm{Cu}$ and $\mathrm{Al} / \mathrm{Ni}$ layers [38]. By processing three-layer steel/vanadium/steel sandwich samples by HPT, there was an analogy of the hybrid multilayer structure (steel/vanadium) to grains in a polycrystalline solid and the Hall-Petch relation was used to explain the relationship between the grain size and thermal stability [39]. In the present work, the Hall-Petch relation was also constructed to explain the relationship between the average width of both phases $\chi$ and also the hardness of the material. Considering that the value of $\chi$ in eq. (2) decreases when the density of phase boundaries increases, the hardness of materials should increase as the value of $\chi$ decreases. This relationship is plotted directly in Figure 5 and it is apparent that the hardness of specimens and the average width $\chi$ of the two phases reasonably fulfill the Hall-Petch relationship, thereby indicating that the hardness of the alloy is quantitatively governed by the value of $\chi$. It is interesting to note that this result provides another example of the use of the Hall-Petch relationship in analyses of ultrafine-grained materials produced using SPD processing techniques [40]. It follows that the effect on the mechanical properties of the increased phase boundaries caused by the refinement in two constituent phases can be explained by the advent of dislocation motion. When the material deforms, the dislocation source continuously releases a large number of mobile dislocations. As the deformation proceeds, the increased phase boundaries lead to a tangling of the dislocations when the dislocations encounter phase boundaries during the HPT process and this significantly improves the hardness of the alloy after deformation. As shown in the TEM images and diffraction patterns in Figure 4j-o, the grains in both austenite and ferrite are refined continuously even at relative large strains, whereas it is shown in Figure 1a that the hardness at the edge of the disk remains nearly unchanged after 1 revolution. This indicates that the grain size in each constituent phase is not the dominant factor in dictating the properties of DSS2205. Instead, it is confirmed from the similarity to the Hall-Petch relationship between the value of $\chi$ and the hardness of the alloy, as shown in Figure 5, that the phase boundary has more influence on the plastic deformation behavior and the mechanical properties of DSS2205.

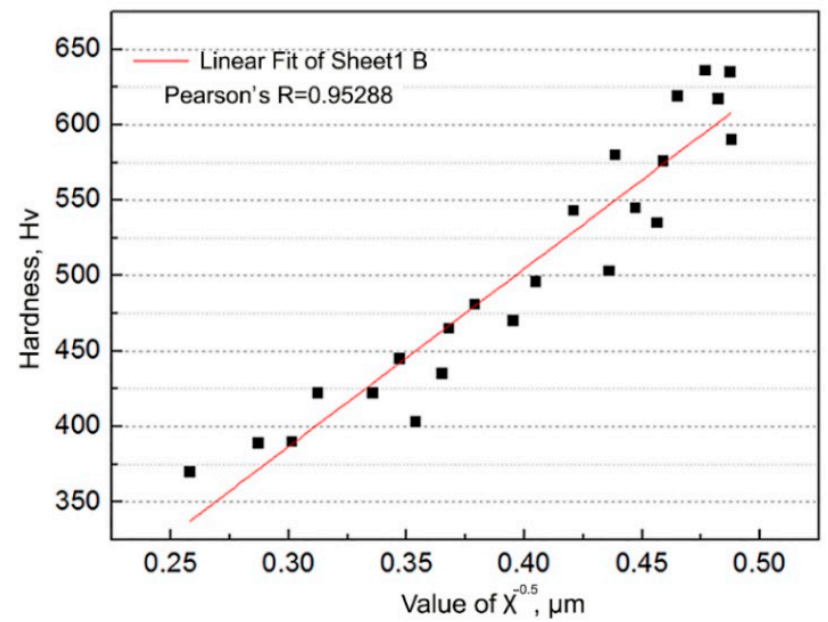

Figure 5. Relationship between hardness of the alloy and value of $\chi^{-0.5}$. 


\section{Summary and Conclusions}

(1) The duplex stainless steel DSS2205 was processed by HPT for up to 20 revolutions. With increasing revolutions and increasing distances from the centers of the specimens, microstructural refinement was improved and the hardness of the alloy increased. After 20 revolutions, the uniformity of the microstructure in the phase domains was also improved.

(2) SPD-induced grain refinement in ferrite and austenite differed from each other during the HPT processing. The ferrite grains were refined through an interaction between deformation dislocations but the grain refinement in austenite was mainly dependent on a mixed mechanism including deformation twinning and an interaction of dislocations and twin boundaries in the early stages of deformation. As the revolutions increased, the austenite grain refinement hindered the mechanism of deformation twinning and dislocation slip became dominant.

(3) The phase boundaries had a significant influence on the plastic deformation behavior and the mechanical properties of DSS2205. After HPT processing, the hardness of the alloy and the average width of the two phase domains were consistent with the predictions of a Hall-Petch relationship.

Author Contributions: Conceptualization, H.D., Y.H. and T.G.L.; validation, H.D., Y.H. and T.G.L.; investigation, M.M. and C.W.T.; data curation, H.D.; writing-original draft preparation, M.M.; writing—review and editing, H.D., Y.H. and T.G.L.; visualization, Y.H. and T.G.L.; supervision, H.D.; project administration, H.D.; funding acquisition, H.D. and T.G.L. All authors have read and agreed to the published version of the manuscript.

Funding: This research was partially funded by CHINESE NATIONAL KEY TECHNOLOGY R\&D PROGRAM, grant number 2012BAE04B01. The research was also partially funded by the EUROPEAN RESEARCH COUNCIL, grant number 267464-SPDMETALS.

Conflicts of Interest: The authors declare no conflict of interest.

\section{References}

1. Valiev, R.Z.; Islamgaliev, R.K.; Alexandrov, I.V. Bulk nanostructured materials from severe plastic deformation. Prog. Mater. Sci. 2000, 45, 103-189. [CrossRef]

2. Koch, C.C. Optimization of strength and ductility in nanocrystalline and ultrafine grained metals. Scr. Mater. 2003, 49, 657-662. [CrossRef]

3. Zhu, Y.T.; Langdon, T.G. The fundamentals of nanostructured materials processed by severe plastic deformation. JOM 2004, 56, 58-63. [CrossRef]

4. Meyers, M.A.; Mishra, A.; Benson, D.J. Mechanical properties of nanocrystalline materials. Prog. Mater. Sci. 2006, 51, 427-556. [CrossRef]

5. Pippan, R.; Wetscher, F.; Hafok, M.; Vorhauer, A.; Sabirov, I. The limits of refinement by severe plastic deformation. Adv. Eng. Mater. 2006, 8, 1046-1056. [CrossRef]

6. Scheriau, S.; Pippan, R. Influence of grain size on orientation changes during plastic deformation. Mater. Sci. Eng. A 2008, 493, 48-52. [CrossRef]

7. Valiev, R.Z.; Estrin, Y.; Horita, Z.; Langdon, T.G.; Zehetbauer, M.J.; Zhu, Y.T. Fundamentals of superior properties in bulk NanoSPD materials. Mater. Res. Lett. 2016, 4, 1-21. [CrossRef]

8. Zhilyaev, A.P.; Kim, B.K.; Nurislamova, G.V.; Baró, M.D.; Szpunar, J.A.; Langdon, T.G. Orientation imaging microscopy of ultrafine-grained nickel. Scr. Mater. 2002, 46, 575-580. [CrossRef]

9. Zhilyaev, A.P.; Nurislamova, G.V.; Kim, B.K.; Baró, M.D.; Szpunar, J.A.; Langdon, T.G. Experimental parameters influencing grain refinement and microstructural evolution during high-pressure torsion. Acta Mater. 2003, 51, 753-765. [CrossRef]

10. Wongsa-Ngam, J.; Kawasaki, M.; Langdon, T.G. A comparison of microstructures and mechanical properties in a Cu-Zr alloy processed using different SPD techniques. J. Mater. Sci. 2013, 48, 4653-4660. [CrossRef]

11. Zhilyaev, A.P.; Langdon, T.G. Using high-pressure torsion for metal processing: Fundamentals and applications. Prog. Mater. Sci. 2008, 53, 893-979. [CrossRef]

12. Valiev, R.Z.; Ivanisenko, Y.V.; Rauch, E.F.; Baudelet, B. Structure and deformation behaviour of armco iron subjected to severe plastic deformation. Acta Mater. 1996, 44, 4705-4712. [CrossRef]

13. Zhilyaev, A.P.; Oh-ishi, K.; Langdon, T.G.; McNelley, T.R. Microstructural evolution in commercial purity aluminum during high-pressure torsion. Mater. Sci. Eng. A 2005, 410, 277-280. [CrossRef] 
14. Xu, C.; Horita, Z.; Langdon, T.G. The evolution of homogeneity in processing by high-pressure torsion. Acta Mater. 2007, 55, 203-212. [CrossRef]

15. Xu, C.; Horita, Z.; Langdon, T.G. The evolution of bomogeneity in an aluminum alloy processed using high-pressure torsion. Acta Mater. 2008, 56, 5168-5176. [CrossRef]

16. Han, J.K.; Liss, K.D.; Langdon, T.G.; Jang, J.I.; Kawasaki, M. Mechanical properties and structural stability of a bulk nanostructured metastable aluminum-magnesium system. Mater. Sci. Eng. A 2020, 796, 140050. [CrossRef]

17. Kawasaki, M.; Figueiredo, R.B.; Langdon, T.G. An investigation of hardness homogeneity throughout disks processed by high-pressure torsion. Acta Mater. 2011, 59, 308-316. [CrossRef]

18. Kawasaki, M.; Figueiredo, R.B.; Langdon, T.G. Twenty-five years of severe plastic deformation: Recent developments in evaluating the degree of homogeneity through the thickness of disks processed by high-pressure torsion. J. Mater. Sci. 2012, 46, 7719-7725. [CrossRef]

19. Estrin, Y.; Molotnikov, A.; Davies, C.H.J.; Lapovok, R. Strain gradient plasticity modelling of high-pressure torsion. J. Mech. Phys. Solids 2008, 56, 1186-1202. [CrossRef]

20. Kecskes, L.J.; Cho, K.C.; Dowding, R.J.; Schuster, B.E.; Valiev, R.Z.; Wei, Q. Grain size engineering of bcc refractory metals: Top-down and bottom-up-Application to tungsten. Mater. Sci. Eng. A 2007, 467, $33-43$. [CrossRef]

21. Lu, C.H.; Remington, B.A.; Maddox, B.R.; Kad, B.; Park, H.S.; Kawasaki, M.; Langdon, T.G.; Meyers, M.A. Laser compression of nanocrystalline tantalum. Acta Mater. 2013, 61,7767-7780. [CrossRef]

22. Maury, N.; Zhang, N.X.; Huang, Y.; Zhilyaev, A.P.; Langdon, T.G. A critical examination of pure tantalum processed by high-pressure torsion. Mater. Sci. Eng. A 2015, 638, 174-182. [CrossRef]

23. Bracke, L.; Verbeken, K.; Kestens, L.; Penning, J. Microstructure and texture evolution during cold rolling and annealing of a high Mn TWIP steel. Acta Mater. 2009, 57, 1512-1524. [CrossRef]

24. Mine, Y.; Tachibana, K.; Horita, Z. Effect of high-pressure torsion processing and annealing on hydrogen embrittlement of type 304 metastable austenitic stainless steel. Metall. Mater. Trans. A 2010, 41A, 3110-3120. [CrossRef]

25. Gutierrez-Urrutia, I.; Raabe, D. Dislocation and twin substructure evolution during strain hardening of an Fe-22 wt.\% Mn-0.6 wt.\% C TWIP steel observed by electron channeling contrast imaging. Acta Mater. 2011, 59, 6449-6462. [CrossRef]

26. Cao, Y.; Wang, Y.B.; An, X.H.; Liao, X.Z.; Kawasaki, M.; Ringer, S.P.; Langdon, T.G.; Zhu, Y.T. Concurrent microstructural evolution of ferrite and austenite in a duplex stainless steel processed by high-pressure torsion. Acta Mater. 2014, 63, 16-29. [CrossRef]

27. Figueiredo, R.B.; Cetlin, P.R.; Langdon, T.G. Using finite element modeling to examine the flow processes in quasi-constrained high-pressure torsion. Mater. Sci. Eng. A 2011, 528, 8198-8204. [CrossRef]

28. Figueiredo, R.B.; Pereira, P.H.R.; Aguilar, M.T.P.; Cetlin, P.R.; Langdon, T.G. Using finite element modeling to examine the temperature distribution in quasi-constrained high-pressure torsion. Acta Mater. 2012, 60, 3190-3198. [CrossRef]

29. Kawasaki, M. Different models of hardness evolution in ultrafine-grained materials processed by high-pressure torsion. J. Mater. Sci. 2014, 49, 18-34. [CrossRef]

30. An, X.H.; Lin, Q.Y.; Wu, S.D.; Zhang, Z.F.; Figueiredo, R.B.; Gao, N.; Langdon, T.G. The influence of stacking fault energy on the mechanical properties of nanostructured $\mathrm{Cu}$ and $\mathrm{Cu}-\mathrm{Al}$ alloys processed by high-pressure torsion. Scr. Mater. 2011, 64, 954-957. [CrossRef]

31. Langdon, T.G. The principles of grain refinement in equal-channel angular pressing. Mater. Sci. Eng. A 2007, 462, 3-11. [CrossRef]

32. Gubicza, J.; El-Tahawy, M.; Huang, Y.; Choi, H.; Choe, H.; Lábár, J.L.; Langdon, T.G. Microstructure, phase composition and hardness evolution in $316 \mathrm{~L}$ stainless steel processed by high-pressure torsion. Mater. Sci. Eng. A 2016, 657, 215-223. [CrossRef]

33. Wang, J.; Li, N.; Anderoglu, O.; Zhang, X.; Misra, A. Detwinning mechanisms for growth twins in face-centered cubic metals. Acta Mater. 2010, 58, 2262-2270. [CrossRef]

34. Wei, Y. The kinetics and energetics of dislocation mediated de-twinning in nano-twinned face-centered cubic metals. Mater. Sci. Eng. A 2011, 528, 1558-1566. [CrossRef]

35. Chen, L.; Yuan, F.P.; Jiang, P.; Wu, X.L. Mechanical properties and nanostructures in a duplex stainless steel subjected to equal channel angular pressing. Mater. Sci. Eng. A 2012, 551, 154-159. [CrossRef] 
36. Ueji, R.; Tsuchida, N.; Terada, D.; Tsuji, N.; Tanaka, Y.; Takemura, A.; Kunishige, K. Tensile properties and twinning behavior of high manganese austenitic steel with fine-grained structure. Scr. Mater. 2008, 59, 963-966. [CrossRef]

37. Cao, Y.; Wang, Y.B.; Figueiredo, R.B.; Chang, L.; Liao, X.Z.; Kawasaki, M.; Zheng, W.L.; Ringer, S.P.; Langdon, T.G.; Zhu, Y.T. Three-dimensional shear-strain patterns induced by high-pressure torsion and their impact on hardness evolution. Acta Mater. 2011, 59, 3903-3914. [CrossRef]

38. Kulagin, R.; Beygelzimer, Y.; Ivanisenko, Y.; Mazilkin, A.; Straumal, B.; Hahn, H. Instabilities of interfaces between dissimilar metals induced by high pressure torsion. Mater. Lett. 2018, 222, 172-175. [CrossRef]

39. Rogachev, S.O.; Khatkevich, V.M.; Nikulin, S.A.; Ignateva, M.V.; Gromov, A.A. High thermally stable multi-layer steel/vanadium alloy hybrid material obtained by high-pressure torsion. Mater. Lett. 2019, 255, 126527. [CrossRef]

40. Balasubramanian, N.; Langdon, T.G. The strength-grain size relationship in ultrafine-grained metals. Metall. Mater. Trans. A 2016, 47A, 5827-5838. [CrossRef]

Publisher's Note: MDPI stays neutral with regard to jurisdictional claims in published maps and institutional affiliations.

(C) 2020 by the authors. Licensee MDPI, Basel, Switzerland. This article is an open access article distributed under the terms and conditions of the Creative Commons Attribution (CC BY) license (http://creativecommons.org/licenses/by/4.0/). 